\title{
A Model OF StRATEGIC DELEGATION IN CONTESTS BETWEEN GROUPS
}

\author{
STEFAN BRANDAUER \\ FLORIAN ENGLMAIER
}

CESIFO WORKING PAPER NO. 1654

CATEgORy 2: Public CHOICE

JANUARY 2006

An electronic version of the paper may be downloaded

- from the SSRN website:

wWw.SSRN.com

- from the CESifo website:

www.CESifo-group.de 


\title{
A Model of StRAtegic Delegation in CONTESTS BETWEEN GROUPS
}

\begin{abstract}
We analyze a contest between two groups where group members have differing valuations for the contested rent. Generically the pivotal group member with the median valuation of the rent will not act himself but will want to send a group member that has preferences different to her own into the contest. The delegation can be either to more or less 'radical' group members. The direction of delegation depends on the order of moves and the relative 'aggressiveness' of the group medians. We show that almost certainly very asymmetric equilibria arise, even if the median group members value the rent (almost) equally. Delegation can lead to a social improvement in terms of resources spent in the contest.
\end{abstract}

JEL Code: D72, D73, D4, P16.

Keywords: strategic delegation, contests, rent seeking, political economy, arms races, distributional conflict.

\author{
Stefan Brandauer \\ University of Munich \\ MGSE \\ Ludwigstr. 28 \\ 80539 Munich \\ Germany \\ stefan.brandauer@Irz.uni-muenchen.de
}

\author{
Florian Englmaier \\ Harvard Business School \\ 25 Harvard Way \\ Baker Library 444A \\ Boston MA 02163 \\ USA \\ fenglmaier@hbs.edu
}

First Version: 30 May 2004

This version: 09 January 2006

We are indebted to Tobias Böhm, Kai Konrad, Matthias Messner, Ray Rees, Hans Zenger and seminar participants at the 2005 Meeting of the Public Choice Society, the European Public Choice Society, the Royal Economic Society, and the Universities of Guelph and Munich for their comments and suggestions. 


\section{Introduction}

Over the last decades, starting with Gordon Tullock's (1980) seminal contribution, contests have been intensely studied, not only in the economics literature but also in political sciences and other related fields. Contests have been used to model a wide array of situations of conflicts, ranging from inter-state conflicts (see e.g. Garfinkel (1990)), over rent seeking (see e.g. Nitzan (1994)), to promotion tournaments (see e.g. Lazear and Rosen (1981)).

We start this paper with the observation that contests are often taking place between groups and, in the light of this observation, allow explicitly for the possibility that the members of these respective groups have differing valuations for the contested rent. This seems quite natural: If a group of producers tries to influence lawmakers to create favorable legislation, the value of this legislation is likely to be different for different group members. As an example one might consider the market for agricultural products where the value of a specific legislation may vary greatly between large industrial farmers and small family run farms.

If we allow for this intra-group heterogeneity, there is a conflict of interests between different members of the group on how much resources to spend in the contest. We take a new perspective on this by taking into account the fact that typically not all the group members are actively participating in the contest, but typically groups assign delegates that act in the contest on behalf of the whole group. In analyzing this delegation problem we assume that the assigned representative will follow her preferences once she is in office. In this respect our analysis has very much the flavor of citizen candidate models a la Besley and Coate (1997) or Osborne and Slivinsky (1996). We show that in our model the Median Voter Theorem is applicable. Thus the delegate's assignment can be modelled as the median voter's choice problem over different delegates' types.

Our set up allows us to analyze under what circumstances radical appointees come into power. The model predicts that in most situations of conflict 'tough' types will interact with 
'weak' types and that it is rather unlikely that two opponents with the same degree of 'radicalization' meet. Initial differences in valuation between the median types in the respective groups are vastly amplified. The initially more 'radical' median voter delegates to a much more radical type whereas the initially less radical median voter accommodates by delegating less aggressively. As a result with delegation the amount of 'waste', i.e. unproductive effort spent in the contest, is generally lower than without delegation. Thus delegation can be, from a social planner's point of view, a desirable feature.

Though contests between groups have been analyzed before, the previous literature had a quite different take on the issue. Baik et al. (2001) look at a situation where two groups compete for a prize and each group member individually decides how much effort to exert in the contest. They find a mixed strategy equilibrium in which only the most 'radical' group member in the respective groups will be active in this situation. Konrad (2004) analyzes a fully discriminating contest ${ }^{1}$ between two groups. After the prize has been allocated to one of the two groups, the members of the winning group internally have a contest to allocate the prize amongst themselves. The outcome depends on inter- and intra-group heterogeneity, and is not driven by free-rider incentives. Other than in our model it is not the median group member that is key to the results but the general heterogeneity within a group. ${ }^{2}$

Also the issue of strategic delegation in the context of contests has been analyzed. Dixit (1987) shows that agents have locally an incentive to commit to exert higher effort in a contest. However he remains silent about how this commitment can work and points out that the specific channels of commitment should be analyzed in depth. We present one possible way to do this and offer a full analysis. Baik and Shogren (1992) build on Dixit

\footnotetext{
${ }^{1}$ In a fully discriminating contest the contestant spending the most wins the prize with certainty.

${ }^{2}$ Dijkstra (1998) and Schoonbeck (2004) also analyze situations of conflicts between groups. They base their analysis on the assumption that joint surplus is maximized. Schoonbeck (2004) focuses on the effect that with increasing group size it becomes more profitable to have just one agent acting in order to overcome the free rider problem in providing rent seeking effort within the group. Dijkstra (1998) makes strong assumptions on contractibility and focuses on the question how agents will support the acting agent in his efforts in the contest.
} 
(1987) and endogenize the order of moves. They can show that the "underdog" always wants to move first whilst the "leader" is happy to wait for his time to come. However, here we come to a different conclusion: In our framework both types would want to be the first mover.

Baik and Kim (1997) analyze a model where the players in a contest can hire agents that are more 'able', i.e. who's effort in the contest has a higher return. These agents can be offered (exogenously given) incentive contracts. They find that there will be never delegation to a less able player. Although their results differ from ours qualitatively, the fact that the initially more radical player hires a more able agent is revocative of our result that the initially more 'radical' median delegates to a more radical representative.

Contests are closely related to all-pay-auctions ${ }^{3}$. But whilst all pay auctions are a special case of fully discriminating contests, we look at not-fully discriminating contests, i.e. the party spending more is not with certainty the winner. Konrad et al. (2004) analyzes delegation in first price all-pay auctions. In their model players can hire other agents to bid for them in the all-pay auction. The agents are incentivized with contracts and they find multiple asymmetric equilibria in this initially symmetric auction game.

The analysis of delegation problems has a long tradition in the political economy literature. Agents often want to delegate certain actions to other agents that have preferences different to their own as the latter are able to commit to carry out certain actions at a future point in time. This logic is very similar to the one used in our argument. A prominent example of this literature is Barro and Gordon`s(1983a, 1983b) model of monetary policy. In their model a central banker faces a time inconsistency problem as his incentives are altered once the private sector has formed its expectations over future inflation. It turns out that the optimal solution is to delegate the monetary authority to a conservative and independent central banker who will never use monetary policy as a macroeconomic stimulus. Similar incentives work in capital taxation. Before capital is accumulated, politicians have an incentive to promise low tax rates. Once the capital is accumulated politicians have clear incentives to

\footnotetext{
${ }^{3}$ Baye et al. (1993) and Hilman and Riley (1989) are examples of applying all-pay-auctions to lobbying.
} 
tax the capital contrary to their past promises. Political economy equilibrium models show that medians voters find it optimal to delegate the taxation authority to a politician that possesses more wealth than they do as the wealthier person can commit more credibly not to overtax the capital ${ }^{4}$. Whilst in these two examples delegation is used to overcome a time inconsistency problem our model focuses on the strategic value of delegation in situations of conflict.

Besley and Coate (2003) analyze centralized versus decentralized provision of public goods and show that for centralized public goods provision the delegates in the districts are strategically chosen such as to maximize the expected return from the negotiations on the federal level. This is close in spirit to Chari et al. (1997) who analyze the congressional split ticket voting behavior in the U.S.. They find that the states are more inclined to vote for democratic politicians to go to congress as they are expected to fight harder for transfers to the states from the federal government.

Our paper relates also to the game theoretic analysis of arms races. If one interprets the groups as nations, the resources as military expenditure and the rent as a foreign policy issue, our model can be seen as a model of arms races. We allow for this interpretation as we believe the model can explain in a simple way several features of arms races. For example Oren (1994) finds that the spending pattern of the conflicting parties in the Indo-Pakistani conflict over Kashmir matches the results of our model. High expenditures by one side are matched with low expenditures of the opponent. Oren (1992) finds the same feature in the US and USSR military spending during the cold war era.

Finally, there is a relation to the social psychology literature on group polarization. Social psychologists, cf. eg. Teger and Pruitt (1967) or Moscovici and Zavalloni (1969), have found that group decisions are distorted towards the extreme with respect to the initial preferences, where the direction depends on the group members initial preferences. Our model could be applied to gain better understanding of the processes within groups that lead to this outcome.

\footnotetext{
${ }^{4}$ See Person and Tabellini (2000) for a comprehensive treatment of this literature.
} 
The remainder of this paper is structured as follows. Section two introduces the basics of the model. We then derive personal preferences over delegate's types and show that the median voter theorem can be applied. In section four we look at a simple version of the model where only one group has to appoint a member that carries out the contest activities. This simplified version already gives us valuable insights into the mechanisms at work. In section five, we look at sequential delegation decisions, in section six the same is done for simultaneous delegation decisions with asymmetric and symmetric group medians respectively. In section seven we look at social welfare by comparing aggregate waste, i.e. total resources spent in the contest. Section eight discusses some extensions. Finally, we conclude in section nine.

\section{Basic Model}

To fix ideas consider two countries $A$ and $B$ that quarrel about a foreign policy issue. Assume this issue can be captured by a rent $R$. First these groups simultaneously have to appoint each a politician to act on their behalf. Then, after observing the representatives' types, these politicians then have to decide how much of a given budget $b_{A}$, in country $A$, and $b_{B}$, in country $B$, to spend in the contest. Finally the rent is allocated. There is no asymmetric information in the model.

The citizens of the two states may have differing valuations of the rent $R$. The valuation of the rent of citizen $i$ in country $A$ is $\alpha^{i} R$, i.e. $\alpha^{i}$ can be seen as the weight placed on the foreign policy issue. $\beta^{j} R$ is the respective valuation for citizen $j$ in country $B . \alpha^{i}$ and $\beta^{j}$ are continuously distributed according to the distribution functions $f_{A}\left(\alpha^{i}\right)$ and $f_{B}\left(\beta^{j}\right)$ within each group. The only restriction we put on the distribution functions is that they have to be bounded on $(0, \bar{\alpha}]$ and $(0, \bar{\beta}]$ respectively, i.e. there exist most 'radical' types $\bar{\alpha}$ and $\bar{\beta}$. The 0 is excluded to avoid technical problems.

An integral part of the model is the contest success function (CSF) $g\left(m_{A} ; m_{B}\right)$ that de- 
termines the probability of winning the contest for a contestant dependent on the resources spent by him, $m_{A}$, and the opponent, $m_{B}$. To model the contest we use a Tullock style contest success function $\frac{m_{A}}{m_{A}+m_{B}}$. Our results would hold for all 'constant returns to scale' contest success functions, i.e. functions of the form $\frac{\theta m_{A}}{\theta m_{A}+\pi m_{B}}$ that are homogenous of degree 0. See the Appendix 10.1 for an exposition with a general constant returns to scale contest success function. We assume $g(0 ; 0)=1 / 2$. To ease the exposition we focus on Tullock's initially proposed function $\frac{m_{A}}{m_{A}+m_{B}}$. As we stick to risk neutrality throughout one can interpret this not only as the winning probability but also as being the share the country secures for itself.

An individual citizen $i$ 's utility function in country $A$ is given by

$$
u_{A}^{i}=\alpha^{i} R \frac{m_{A}}{m_{A}+m_{B}}+\left(b_{A}-m_{A}\right)
$$

and the utility function for citizen $j$ in country $B$ is given by

$$
u_{B}^{j}=\beta^{j} R \frac{m_{B}}{m_{A}+m_{B}}+\left(b_{B}-m_{B}\right)
$$

This states that utility is increasing in the (expected) rent and decreasing in the resources spent by the country in the contest. This cost $-m_{i}$ with $i=\{A, B\}$ can be considered as the foregone public good which is produced with a simple linear production function from the exogenously given budget $b_{i}$ with $i=\{A, B\}$ not spent in the contest. Alternatively think of the contest expenditure financed by a equal per-capita-tax. We assume for now that the budget restrictions are never binding and neglect them in the course of this analysis. We will discuss these issues in our Extensions section where we also introduce heterogeneity in the cost of provision of the public good.

We proceed from here by first deriving the equilibrium of the contest stage dependent on the politician's types. Then we use our results to derive in the next section the citizens' preferences over politicians' types.

In the contest stage the two agents $i$ (for country $A$ ) and $j$ (for country $B$ ) in charge 
maximize their utility by deciding upon $m_{A}$ and $m_{B}$.

$$
\begin{aligned}
& \max _{m_{A}} u_{A}^{i}=\alpha^{i} R \frac{m_{A}}{m_{A}+m_{B}}+\left(b_{A}-m_{A}\right) \\
& \max _{m_{B}} u_{B}^{j}=\beta^{j} R \frac{m_{B}}{m_{A}+m_{B}}+\left(b_{B}-m_{B}\right)
\end{aligned}
$$

From the two first order conditions of this problem we can solve for the reaction functions

$$
m_{A}=\sqrt{m_{B} R \alpha^{i}}-m_{B} \text { and } m_{B}=\sqrt{m_{A} R \beta^{j}}-m_{A}
$$

and the equilibrium values of $m_{A}^{*}$ and $m_{B}^{*}$ which are uniquely determined by

$$
m_{A}^{*}=R \frac{\left(\alpha^{i}\right)^{2} \beta^{j}}{\left(\alpha^{i}+\beta^{j}\right)^{2}} \quad \text { and } \quad m_{B}^{*}=R \frac{\alpha^{i}\left(\beta^{j}\right)^{2}}{\left(\alpha^{i}+\beta^{j}\right)^{2}} .
$$

They depend only on the politicians' types and on the size of the rent under consideration ${ }^{5}$.

It will be useful in the further analysis of the model to note some properties of these equilibrium values. The equilibrium spending of a politician is strictly increasing in her own type, i.e. $\frac{\partial\left(m_{A}^{*}\right)}{\partial \alpha^{i}}>0$ and $\frac{\partial\left(m_{B}^{*}\right)}{\partial \beta^{j}}>0$. It is increasing (decreasing) in the other politician's type if the politician is more (less) radical then the other politician.

$$
\frac{\partial\left(m_{A}^{*}\right)}{\partial \beta}=R \frac{\alpha^{2}(\alpha-\beta)}{(\alpha+\beta)^{3}}\left\{\begin{array}{ll}
>0 & \text { if } \quad \alpha>\beta \\
=0 & \text { if } \quad \alpha=\beta \\
<0 & \text { if } \quad \alpha<\beta
\end{array} \text { and } \frac{\partial\left(m_{B}^{*}\right)}{\partial \alpha}=R \frac{\beta^{2}(\beta-\alpha)}{(\alpha+\beta)^{3}}\left\{\begin{array}{ccc}
>0 & \text { if } \alpha<\beta \\
=0 & \text { if } & \alpha=\beta \\
<0 & \text { if } & \alpha>\beta
\end{array}\right.\right.
$$

It facilitates intuition of our results later on to note already here how these equilibrium values for $m_{A}$ and $m_{B}$ behave in the limit with respect to the acting politicians' types. The equilibrium contest spending does not go to infinity if the politician's valuation of the rent goes to infinity, but is bounded. If the politician's valuation of the rent goes to infinity the equilibrium contest spending stays bounded with

$$
\lim _{\alpha^{i} \rightarrow \infty} m_{A}=R \beta^{j} \text { and } \lim _{\beta^{j} \rightarrow \infty} m_{B}=R \alpha^{i} .
$$

\footnotetext{
${ }^{5}$ Note that for $\alpha^{i}=\beta^{j}=1$, i.e. the situation analyzed by Tullock (1980) the values not surprisingly boil down to his solution, namely $m_{A}^{*}=m_{B}^{*}=\frac{R}{4}$.
} 


\section{Individual Preferences over Politician Types}

This section uses our results from above on the contest stage game to derive individual citizens' preferences over politicians' types. From above we know the equilibrium values of $m_{A}$ and $m_{B}$ are uniquely determined by

$$
m_{A}^{*}=R \frac{\left(\alpha^{i}\right)^{2} \beta^{j}}{\left(\alpha^{i}+\beta^{j}\right)^{2}} \quad \text { and } \quad m_{B}^{*}=R \frac{\alpha^{i}\left(\beta^{j}\right)^{2}}{\left(\alpha^{i}+\beta^{j}\right)^{2}} .
$$

Now we are interested in the question what kind of politician $\alpha^{P}$ a citizen $i$ would like to send into the contest, taking country $B^{\text {'s }}$ politician choice $\beta^{P}$ as given. Would he want to act himself or would he want to have a politician with a lower or higher valuation $\alpha^{P}$ than his own to act on his behalf?

The problem of country $A$ citizen $i$ is given by

$$
\max _{\alpha^{P}} \quad u^{i}=\alpha^{i} R \frac{m_{A}\left(\alpha^{P}, \beta^{P}\right)}{m_{A}\left(\alpha^{P}, \beta^{P}\right)+m_{B}\left(\alpha^{P}, \beta^{P}\right)}+\left(b_{A}-m_{A}\left(\alpha^{P}, \beta^{P}\right)\right) .
$$

Using our results for $m_{A}^{*}$ and $m_{B}^{*}$ from above the problem becomes

$$
\max _{\alpha^{P}} \quad \alpha^{i} R \frac{\left(\alpha^{P}\right)^{2} \beta^{P}}{\left(\alpha^{P}\right)^{2} \beta^{P}+\alpha^{P}\left(\beta^{P}\right)^{2}}-R \frac{\left(\alpha^{P}\right)^{2} \beta^{P}}{\left(\alpha^{P}+\beta^{P}\right)^{2}}
$$

and we can solve for the reaction function

$$
\alpha^{P^{*}}=\frac{\beta^{P} \alpha^{i}}{2 \beta^{P}-\alpha^{i}}
$$

Inspecting the comparative statics we find that the optimal action increases in the citizen's type $\frac{\partial \alpha^{P^{*}}}{\partial \alpha^{i}}=2\left(\frac{\beta^{P}}{2 \beta^{P}-\alpha^{i}}\right)^{2}>0$ and decreases in the type of the other country's politician, $\frac{\partial \alpha^{P^{*}}}{\partial \beta^{P}}=-\left(\frac{\alpha^{i}}{2 \beta^{P}-\alpha^{i}}\right)^{2}<0$. Thus we can clearly see that delegation decisions of the countries are strategic substitutes. This is an interesting observation in itself as it is in the analysis of contests seldomly the case that such a clear-cut case on strategic substitutability or complementarity can be made. 


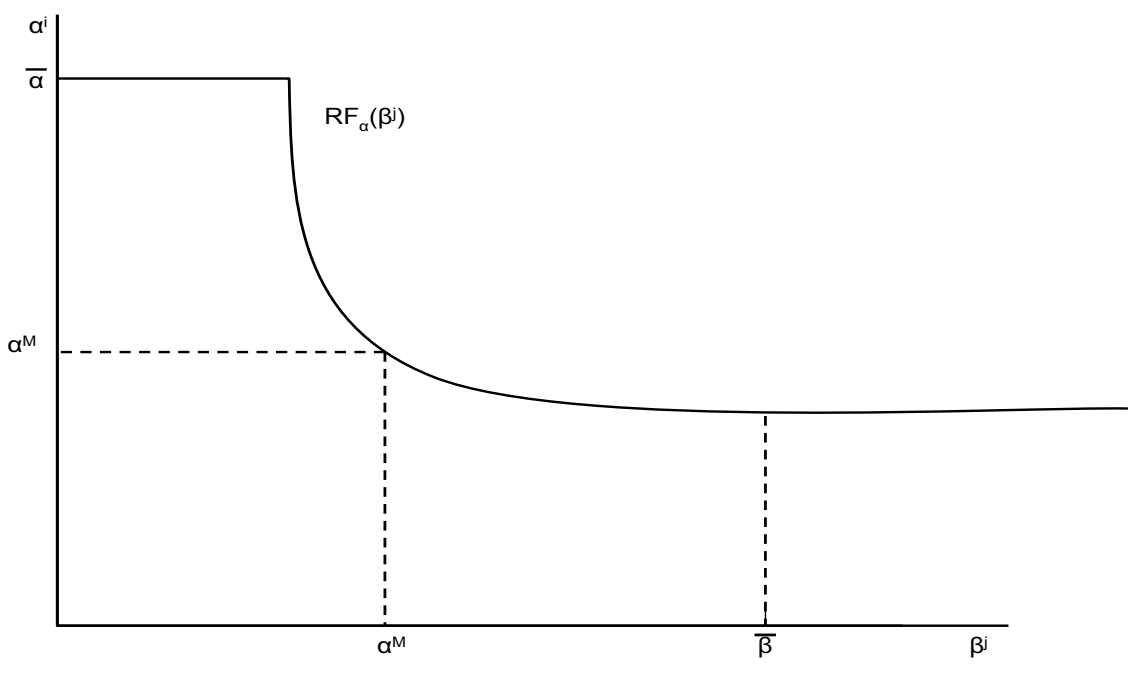

Figure 1: Reaction Function for one-sided delegation

Note that in the case where country $B$ 's politician has exactly the same valuation as the country $A$ citizen under consideration, $\beta^{P}=\alpha^{i}$, this country $A$ citizen prefers to act himself, $\alpha^{P^{*}}=\alpha^{i}$.

Due to technical properties of the contest success function the country $A$ citizen would like to delegate to a politician with a negative valuation for cases where he is confronted with a country $B$ politician with a very low valuation $\left(\beta^{P}<\frac{\alpha^{M} \bar{\alpha}}{\left(2 \bar{\alpha}-\alpha^{M}\right)}\right)$. As we restricted the type space to positive valuation types we can show that in all those cases the utility of citizen $i$ is strictly increasing in $\alpha^{P}$ (see Appendix 10.2) and thus he wants to delegate to the most radical type $\bar{\alpha}$. This leads to a vertical piece in the reaction function (see Figure 1 ). Thus the reaction function is characterized by $\alpha^{P^{*}}=\frac{\beta^{M} \alpha^{M}}{2 \beta^{M}-\alpha^{M}}$ if $\frac{\beta^{M} \alpha^{M}}{2 \beta^{M}-\alpha^{M}}<\bar{\alpha}$ and by $\alpha^{P^{*}}=\bar{\alpha}$ otherwise.

In order to analyze the delegation problem we proceed now by showing that in our context the Median Voter Theorem (MVT) is applicable.

Following Black (1948) we know that in any one dimensional policy problem the median 
voters most preferred policy choice will win any pairwise vote over any other policy candidate if the agents exhibit single peaked preferences over the policy choices.

First note that we deal with a one dimensional policy problem, as the question at hand is in the end what amount $m_{A}$ to spend in the contest. As we have shown above the decision how much to spend corresponds one to one to the decision which delegate to have in the contest. Now for the Median Voter Theorem to be applicable we have to show single peakedness.

There is a one-to-one mapping from the spending decision to the type decision as any pair $\left(m_{A}, m_{B}\right)$ can be generated by choosing a pair of politicians $\left(\alpha^{P}, \beta^{P}\right)$ and the functions for $m_{A}$ and $m_{B}$ respectively are strictly increasing in the politician's type. Thus we focus only on the decision over types. Above we derived the reaction function in the delegate's type space for an arbitrary group member. Now we show that the utility has a unique peak on this reaction function for any group member for any given delegate type of the other group.

The optimal value of $\alpha^{P}$ for an arbitrary country $A$ citizen $i$ is given by $\alpha^{P}=\frac{\alpha^{i} \beta^{P}}{2 \beta^{P}-\alpha^{i}}$. The derivative of $i$ 's utility function is given by

$$
\frac{\partial u_{A}}{\partial \alpha^{P}}=\frac{R \beta^{P}}{\left(\alpha^{P}+\beta^{p}\right)^{3}}\left(\alpha^{i} \alpha^{P}+\alpha^{i} \beta^{P}-2 \alpha^{P} \beta^{P}\right)
$$

Thus we know that

$$
\operatorname{sgn}\left(\frac{\partial u_{A}}{\partial \alpha^{P}}\right)=\operatorname{sgn}\left(\alpha^{i} \alpha^{P}+\alpha^{i} \beta^{P}-2 \alpha^{P} \beta^{P}\right)
$$

Now plugging in $k \frac{\alpha^{i} \beta^{P}}{2 \beta^{P}-\alpha^{i}}$ for $\alpha^{P}$ and checking for $k<1$ (below the reaction function) and $k>1$ (above the reaction function) gives

$$
\operatorname{sgn}\left(\frac{\partial u}{\partial \alpha^{P}}\right)=+1 \quad \text { for } \quad k<1
$$

and 


$$
\operatorname{sgn}\left(\frac{\partial u}{\partial \alpha^{P}}\right)=-1 \quad \text { for } \quad k>1
$$

Thus, as needed for single peakedness, utility is strictly increasing in $\alpha^{P}$ below the optimal choice and strictly decreasing in $\alpha^{P}$ above the optimal choice. As argued above for the vertical part of the reaction functions where the optimal choice of $\alpha^{P}$ is restricted by $\bar{\alpha}$ utility is strictly increasing until $\bar{\alpha}$. Single peakedness is therefore automatically ensured and the Median Voter Theorem is applicable.

Lemma 1 Given the one dimensional policy problem with single peaked preferences we can analyze the delegation problem as the median voter's optimization problem.

\section{One-sided Delegation}

A natural starting point for the analysis of the delegation decision is the situation where only one country delegates. Without loss of generality we restrict our analysis to the case where country $A$ has this option. An interpretation of this situation would be that the population in country $B$ has homogenous valuation of the rent or that in country $B$ institutional features hinder delegation.

In the case of one sided delegation we only have to closely inspect the above derived reaction function of country $A$ 's median voter $\alpha^{M}$. As shown above his valuation determines country A's delegation decision. To ease exposition we assume without loss of generality that in country $B$ the median type acts in the contest.

Proposition 2 In the case of onesided delegation the optimal delegation decision depends solely on the type of the median and on the type of the other country's acting politician. The best response is given by $\alpha^{P^{*}}=\frac{\beta^{M} \alpha^{M}}{2 \beta^{M}-\alpha^{M}}$ if $\frac{\beta^{M} \alpha^{M}}{2 \beta^{M}-\alpha^{M}}<\bar{\alpha}$ and by $\alpha^{P^{*}}=\bar{\alpha}$ otherwise. 
A closer inspection of this reaction function tells us more about when country $a$ wants to delegate to more radical or less radical politicians.

Proposition 3 If $\alpha^{M}<\beta^{M}$ the median group member prefers to send a group member that values the rent less than him into the contest (delegation to a less aggressive type).

If $\alpha^{M}>\beta^{M}$ the median group member prefers to send a group member that values the rent more than him into the contest (delegation to a more aggressive type).

If $\alpha^{M}=\beta^{M}$ the median group member prefers to act himself in the contest, i.e. $\alpha^{P^{*}}=\alpha^{M}$.

Here we already see the basic logic of delegation at work. Delegation leads to an amplification of initial differences which makes the actual contest more asymmetric. We will use the insights from this simple case in the analysis of what follows.

\section{Sequential Delegation}

Now we allow both countries to decide which citizen to send into the contest (two sided delegation). We first look at an analytically simpler situation in which country $A$ has to appoint its politician before country $B$ does. In what follows we refer to this case as sequential delegation.

We solve the problem by backwards induction and first have a look at country $B$ 's problem where the median citizen has to decide upon delegation.

$$
\max _{\beta^{P}} u_{B}^{M}=\beta^{M} R \frac{m_{B}}{m_{A}+m_{B}}+\left(b_{B}-m_{B}\right) .
$$

Using our results for $m_{A}$ and $m_{B}$ and deriving the first order condition we get the by now familiar expression for the optimal choice of $\beta^{P^{*}}$ :

$$
\beta^{P^{*}}=\frac{\alpha^{P} \beta^{M}}{2 \alpha^{P}-\beta^{M}} .
$$


Lemma 4 The best response function for $\beta^{M}$ is given by $\beta^{P^{*}}=\frac{\alpha^{P} \beta^{M}}{2 \alpha^{P}-\beta^{M}}$ if $\frac{\beta^{M} \alpha^{M}}{2 \alpha^{M}-\beta^{M}}<\bar{\alpha}$ and by $\beta^{P^{*}}=\bar{\beta}$ otherwise.

Anticipating the behavior of the country $B$ median and the behavior of the politicians the country $A$ median faces the following optimization problem:

$$
\max _{\alpha^{P}} \quad u_{A}^{M}=\alpha^{M} R \frac{m_{A}}{m_{A}+m_{B}}+\left(b_{A}-m_{A}\right)
$$

Using the equilibrium values of $m_{A}^{*}, m_{B}^{*}$ and $\beta^{P^{*}}$, this becomes:

$$
\max _{\alpha^{P}} \quad R\left[\frac{\alpha^{M}}{2}-\beta^{M}\left(\beta^{M}+2 \alpha^{M}\right) \frac{1}{4 \alpha^{P}}\right]
$$

As can be seen easily, utility strictly increases in $\alpha^{P}$. Thus it is optimal to choose $\alpha^{P^{*}}=\bar{\alpha}$. This means that it is optimal for the country $A$ median to delegate the negotiations to the most aggressive group member, irrespective of his relative aggressiveness as compared to country B's median.

Plugging this into $\beta^{M}$ 's best response function we get $\beta^{P^{*}}=\frac{\bar{\alpha} \beta^{M}}{2 \bar{\alpha}-\beta^{M}}$.

Proposition 5 In the sequential move game the first mover chooses to delegate as radical as possible $\left(\alpha^{P^{*}}=\bar{\alpha}\right)$ whereas the second mover accommodates $\left(\beta^{P^{*}}=\frac{\bar{\alpha} \beta^{M}}{2 \bar{\alpha}-\beta^{M}}\right)$. For $\bar{\alpha} \rightarrow \infty$ we find that $\beta_{b}^{*}$ converges to $\frac{\beta^{M}}{2}$. This result is independent of whether the first or the second moving median is more radical.

This result deserves some consideration for several reasons. First of all, it tells us that the result in the delegation case will be more pronounced then the one in standard contest models. While standard models of contests predict also asymmetric equilibria for symmetric players in a sequential situation, the model of delegation in contests predicts extremely asymmetric equilibria in its sequential version. 
Second, the model gives us a clear prediction of the way in which the asymmetry works: The country that is able to appoint a politician first has a first mover advantage as the appointment of a politician presents a fait accompli to the second country. Namely, the first country will use its first moving advantage in order to delegate to its most radical member, thereby making fighting for the rent more costly for the other group. Consequently, in equilibrium the share of the rent (and the utility for the median type) the first moving country can get will be significantly greater than the other country's share (see Appendix 10.3). This holds as long as $\bar{\alpha}$ is sufficiently large, namely $\bar{\alpha}>2 \beta^{M}$. I.e., as long as delegation is a powerful instrument it ensures an advantage. The result is particularly striking for groups that are absolutely identical.

Note that our result that both countries prefer to have the first moving advantage contradicts Baik and Shogren's (1992) result that the 'underdog' (in our case the median of the country with the less aggressive median) wants to move first whilst the 'top dog' happily waits for its turn.

\section{Simultaneous Delegation}

We now look at the situation where the medians delegate simultaneously. Using the above derived equilibrium values of the final stage game we can solve for the best reply functions of the median types in the type space.

The problem of the median voter in countries $A$ and $B$ respectively is to choose a politician that will maximize their utility given her behavior in the final stage game

$$
\begin{aligned}
\max _{\alpha^{P}} u_{A}^{M} & =\alpha^{M} R \frac{m_{A}}{m_{A}+m_{B}}+\left(b_{A}-m_{A}\right) \\
\max _{\beta^{P}} u_{B}^{M} & =\beta^{M} R \frac{m_{B}}{m_{A}+m_{B}}+\left(b_{B}-m_{B}\right) .
\end{aligned}
$$


We can use the equilibrium values for $m_{A}$ and $m_{B}$ and derive the first order conditions and get again the equilibrium delegation functions in the politician type space:

$$
\begin{aligned}
& \alpha^{P^{*}}=\frac{\beta^{M} \alpha^{M}}{2 \beta^{M}-\alpha^{M}} \text { if } \frac{\beta^{M} \alpha^{M}}{2 \beta^{M}-\alpha^{M}}<\bar{\alpha} \text { and } \alpha^{P^{*}}=\bar{\alpha} \text { otherwise for country } A . \\
& \beta^{P^{*}}=\frac{\beta^{M} \alpha^{M}}{2 \alpha^{M}-\beta^{M}} \text { if } \frac{\alpha^{M} \beta^{M}}{2 \alpha^{M}-\beta^{M}}<\bar{\beta} \text { and } \beta^{P^{*}}=\bar{\beta} \text { otherwise for country } B .
\end{aligned}
$$

These functions have an interesting property. They are symmetric around the bisecting line. And, if one neglects for a moment the restriction that $\alpha^{P^{*}}<\bar{\alpha}$ and $\beta^{P^{*}}<\bar{\beta}$, we can see that for $\alpha^{M}=\beta^{M}$, i.e. perfectly symmetrical countries, they coincide for positive values of $\alpha^{P^{*}}$ and $\beta^{P^{*}}$. If however $\alpha^{M} \neq \beta^{M}$ they do not intersect at all, i.e. there does not exist an equilibrium in pure strategies. We will treat those cases separately.

\subsection{Simultaneous Delegation - Asymmetry}

We start with the generic case where countries' medians differ in their valuation, i.e. $\alpha^{M} \neq$ $\beta^{M}$. Without loss of generality we focus on the case where $\alpha^{M}<\beta^{M}$. In this case we can use our above derived results and find that the unique intersection of the best response functions is given by the point where $\beta^{M}$ delegates to his most radical option, $\beta^{P^{*}}=\bar{\beta}$, and $\alpha^{M}$ accommodates by choosing $\alpha^{P^{*}}=\frac{\bar{\beta} \alpha^{M}}{\left(2 \bar{\beta}-\alpha^{M}\right)}$. It is interesting that we get this result of extreme polarization independent of the difference in the median types, i.e. initially only marginal differences are drastically amplified and lead to very asymmetric equilibria.

Proposition 6 If countries are asymmetric, i.e. $\alpha^{M}<\beta^{M}$ (w.l.o.g.), there is a unique equilibrium characterized by $\beta^{M}$ delegating to $\beta^{P^{*}}=\bar{\beta}$, i.e. as radical as possible, and $\alpha^{M}$ accommodating and delegating to $\alpha^{P^{*}}=\frac{\bar{\beta} \alpha^{M}}{\left(2 \bar{\beta}-\alpha^{M}\right)}$. This polarization is independent of the degree of the countries' asymmetry.

Note that even if country $B$ can delegate very extremely, i.e. $\bar{\beta} \rightarrow \infty$, we get country $A$ still not delegating to the lowest type but $\alpha^{P^{*}}$ converges to $\alpha^{M} / 2$. 


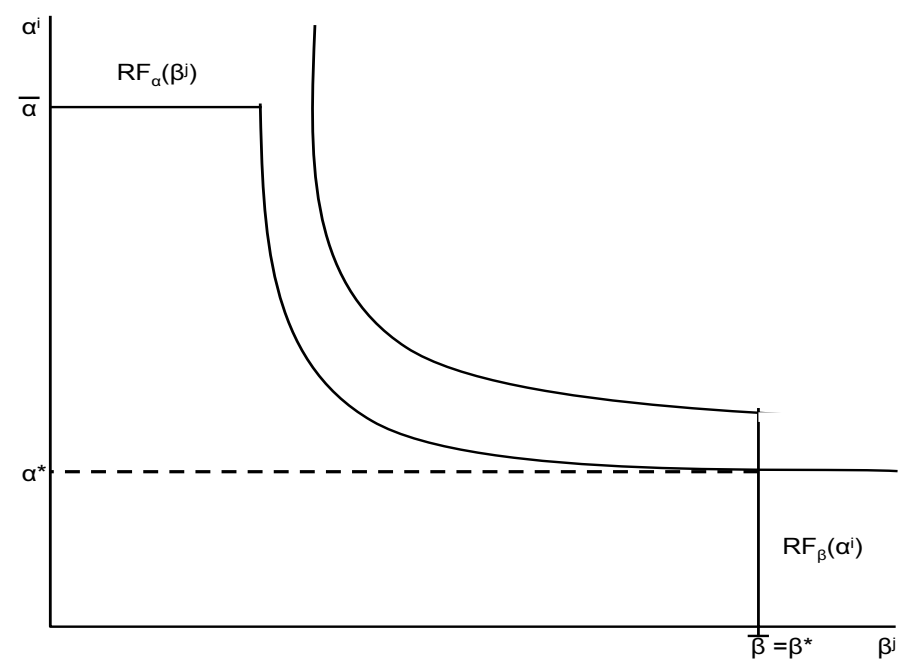

Figure 2: Simultaneous Delegation - Asymmetry

Note that standard models of contests predict asymmetric equilibria as well, if the contestants valuation of the rent is different. It is easy to show however that in our case the asymmetry will be more pronounced. Moreover, as one can see in Figure 3, even minuscule variations in a country's (here country $B^{\prime} s$ ) median voter (and thus shifts in the reaction function) might lead to very dramatic changes in the Equilibrium (here from $E$ to $E^{\prime}$ ).

Note however, that the extreme nature of these equilibria depends on the restricted support for $\beta^{P^{*}} \leq \bar{\beta}$. If we allow for unbounded support this equilibrium seizes to exist and we do not find any pure strategy equilibrium (see Figure 4). As the strategy set in this case is not compact we do not find a mixed strategy equilibrium, either. The intuition seems to be straightforward. Because no matter how far we push $\bar{\alpha}$ out, the extremely asymmetric nature of the pure strategy equilibrium persists. The very moment we go to the limit of $\bar{\alpha} \rightarrow \infty$ the nature of the (mixed strategy) equilibrium would change non-continuously. However, as the existence of an infinitely radical citizen seems to be not the empirically most relevant case we neglect this particularity in the remainder of the analysis and assume that there exist maximum types $\bar{\alpha}$ and $\bar{\beta}$. 


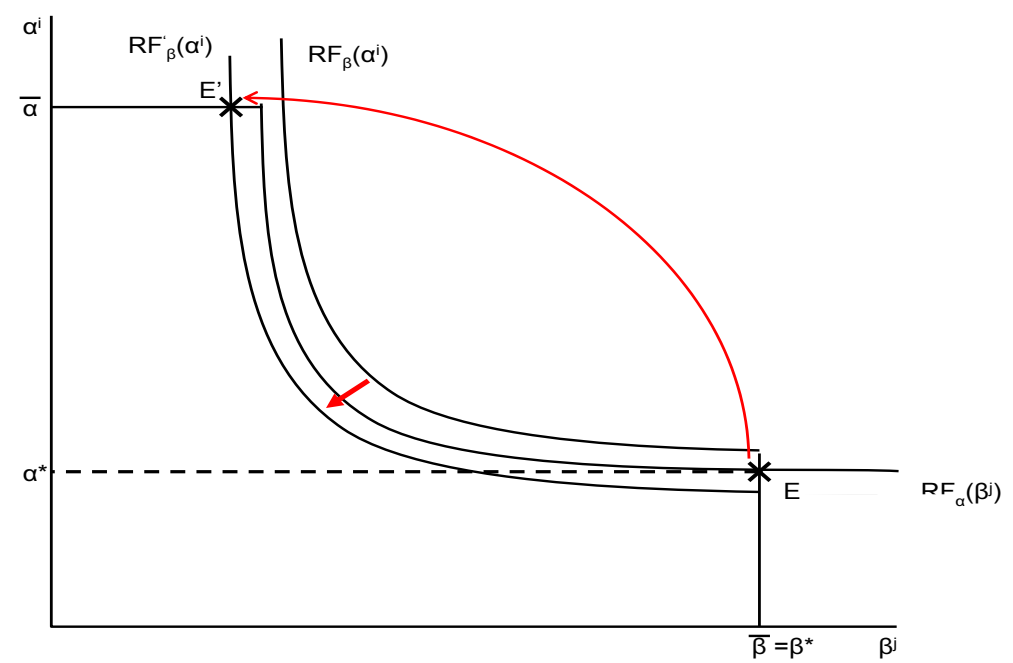

Figure 3: Simultaneous Delegation - Equilibrium Movement

\subsection{Simultaneous Delegation - Symmetry}

In the non generic case where $\alpha^{M}=\beta^{M}=\gamma$ countries are perfectly symmetric in terms of the technological prerequisites and the preferences of the median citizen. As noted above, in this case there exists a continuum of equilibria as the reaction function coincide (see Figure $4)$.

Proposition 7 For $\alpha^{M}=\beta^{M}=\gamma$ a continuum of equilibria exists in the simultaneous delegation game.

There is no a priori reason why one of these equilibria should have more appeal than the others but we can compare them with respect to the utility country $A$ 's median receives in them. From that we can see which equilibrium this agent would choose if he had the power to determine which equilibrium should be played. 


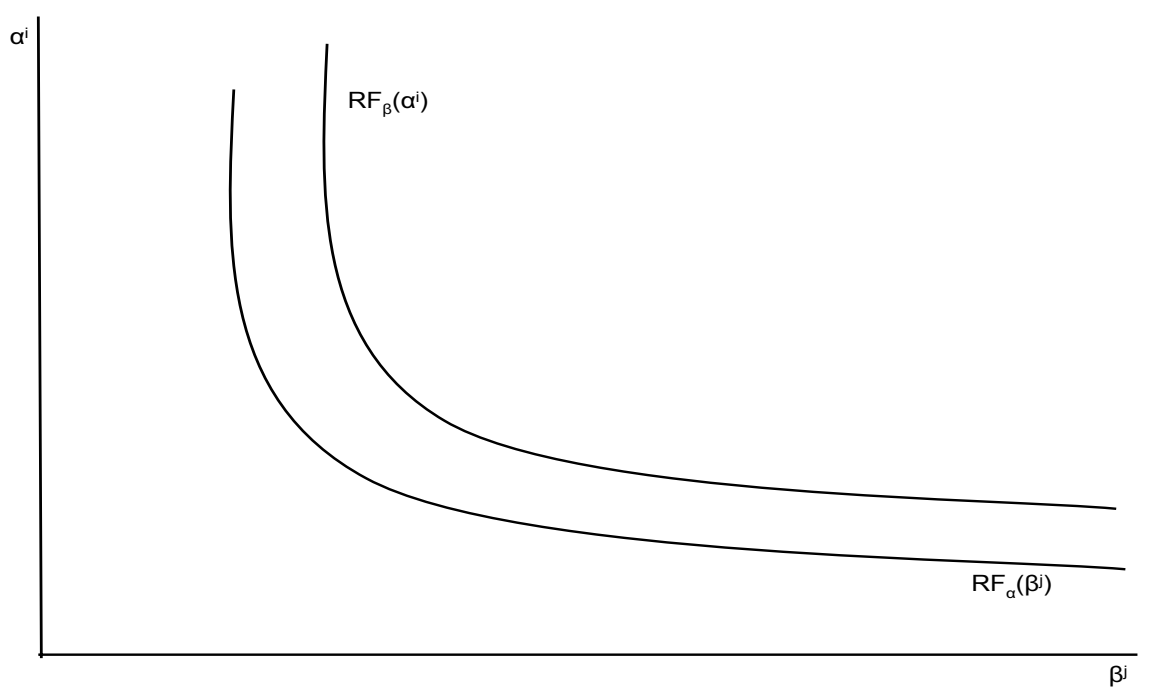

Figure 4: Asymmetric countries with unbounded support - no equilibrium

As a first step we write $m_{A}$ and $m_{B}$ as functions of $\alpha^{P}$. Note that we replace $\beta^{M}$ and $\alpha^{M}$ with $\gamma$ as $\alpha^{M}=\beta^{M}=\gamma$ holds):

$$
m_{A}=R \frac{\left(2 \alpha^{P} \gamma-\gamma^{2}\right)}{4 \alpha^{P}} \text { and } m_{B}=R \frac{\gamma^{2}}{4 \alpha^{P}}
$$

Using this expressions we can write the utility of country $A^{\prime}$ 's median voter as $u_{A}^{M}=$ $\frac{1}{2} R \gamma-\frac{R \gamma^{2}}{4 \alpha^{P}}$. We can easily see, that this expression strictly increases in $\alpha^{P}$ and reaches a maximum at $\alpha^{P}=\bar{\alpha}$.

Lemma 8 Country A median prefers most the equilibrium where he delegates to his most radical option $\bar{\alpha}$.

This result parallels the analysis of our sequential case where it was most desirable to be the first mover and delegate as extreme as possible. Thus it seems hardly surprising that in this case this type of equilibrium is preferred, too. 


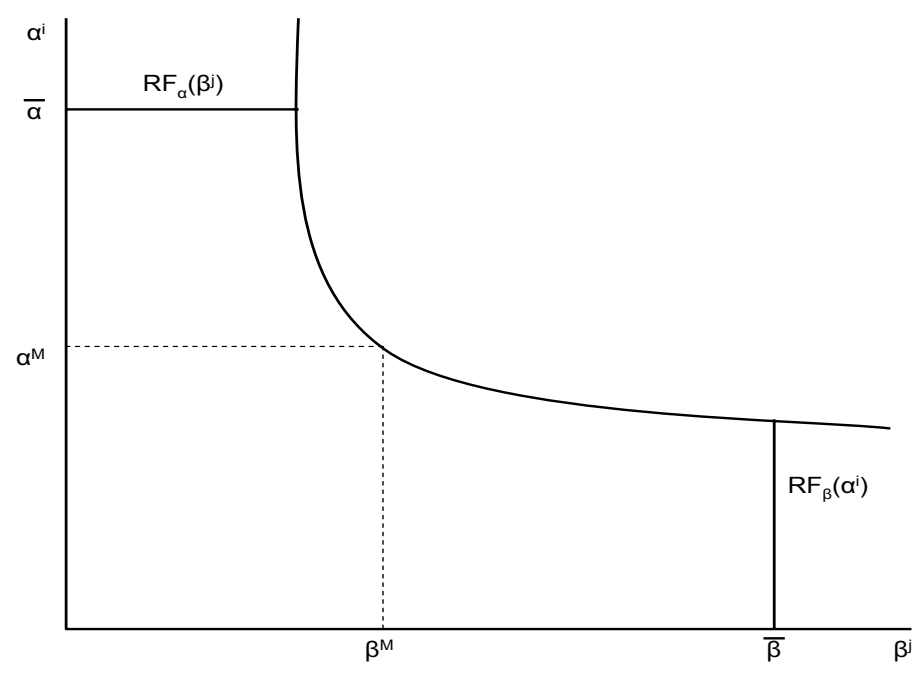

Figure 5: Simultaneous Delegation - Symmetry

\section{Aggregate Waste under Delegation and No Delega- tion}

In this section we are going to analyze whether there is an effect of delegation on social welfare. In the analysis of contests social welfare is measured by the resources that are unproductively spent in the contest, i.e. the waste that is generated. We compare whether aggregate waste differs in a situation where delegation is possible as compared to a situation where the median type himself acts. The situation where the median voter acts himself is the relevant comparison as we know that the policy suggested by the median voter would win every election. We have shown above, that the Median Voter Theorem is applicable in our context. So without the possibility to delegate we know that always the median voter's most preferred policy would be implemented.

We show below that delegation has non-trivial effects on aggregate waste. This may imply interesting policy implications for designing optimal contests as a social planner interested 
in reducing the amount of resources spent in contests can try to design the structure of the contest such that groups are able or even forced to delegate.

\subsection{Aggregate Waste with one--sided Delegation}

We start with the situation where only one country, without loss of generality we again assume it is country $A$, can delegate. Aggregate waste in the case of no delegation, $W_{n D}$, can be written as

$$
W_{n D}=m_{A}+m_{B}=R \frac{\alpha^{M} \beta^{M}}{\alpha^{M}+\beta^{M}}
$$

From the equilibrium values for spending in the contest $m_{A}^{*}=R \frac{\left(\alpha^{i}\right)^{2} \beta^{j}}{\left(\alpha^{i}+\beta^{j}\right)^{2}}$ and $m_{B}^{*}=$ $R \frac{\alpha^{i}\left(\beta^{j}\right)^{2}}{\left(\alpha^{i}+\beta^{j}\right)^{2}}$ and from the equilibrium values for the acting politicians, $\alpha^{P^{*}}=\frac{\beta^{M} \alpha^{M}}{2 \beta^{M}-\alpha^{M}} \quad$ and $\quad \beta^{j}=$ $\beta^{M}$ we can derive the aggregate waste in the case of delegation, $W_{D}$, as

$$
W_{D}=m_{A}^{*}+m_{B}^{*}=\frac{1}{2} R \alpha^{M}
$$

The difference in aggregate waste, $\Delta W=W_{n D}-W_{D}$, can now be easily calculated.

$$
\operatorname{sgn}[\Delta W]=\operatorname{sgn}\left[R \frac{\beta^{M} \alpha^{M}}{\beta^{M}+\alpha^{M}}-\frac{1}{2} R \alpha^{M}\right]=\operatorname{sgn}\left[\beta^{M}-\alpha^{M}\right]=\left\{\begin{array}{ccc}
+1 & \text { if } \beta^{M} \geq \alpha^{M} \\
-1 & \text { if } \quad \beta^{M}<\alpha^{M}
\end{array}\right.
$$

We see that there is a reduction in aggregate waste whenever the country $B$ median, who acts herself, is more radical. The intuition is that country $A$ by delegating in this situation has the chance to back down and amplify the initial difference. By doing so the contest is more biased and less controversial. If however the country $A$ median is initially more radical the difference is also more pronounced but the median in country $B$ cannot back down by delegating downwards. Thus the controversy is worsened. 


\subsection{Aggregate Waste with Sequential Delegation}

Without loss of generality we again assume it is country $A$ that delegates first. Recall from above that aggregate waste in the case of no delegation, $W_{n D}$, can be written as $W_{n D}=$ $R \frac{\alpha^{M} \beta^{M}}{\alpha^{M}+\beta^{M}}$.

Using the equilibrium values of $m_{A}^{*}$ and $m_{B}^{*}$ and recalling the results of delegation, $\alpha^{P^{*}}=\bar{\alpha}$ and $\beta^{P^{*}}=\frac{\bar{\alpha} \beta^{M}}{2 \bar{\alpha}-\beta^{M}}$, we can derive the aggregate waste in the case of delegation, $W_{D}$, as

$$
W_{D}=m_{A}^{*}+m_{B}^{*}=\frac{1}{2} R \beta^{M} .
$$

For the difference in aggregate waste, $\Delta W=W_{n D}-W_{D}$, it holds that

$$
\operatorname{sgn}[\Delta W]=\operatorname{sgn}\left[R \frac{\beta^{M} \alpha^{M}}{\beta^{M}+\alpha^{M}}-\frac{1}{2} R \beta^{M}\right]=\operatorname{sgn}\left[\alpha^{M}-\beta^{M}\right]=\left\{\begin{array}{ccc}
+1 & \text { if } \beta^{M} \leq \alpha^{M} \\
-1 & \text { if } \quad \beta^{M}>\alpha^{M}
\end{array} .\right.
$$

The intuition is that if the right, i.e. the initially more radical, country can move first, the asymmetry is increased and delegation works the right way and reduces waste. If it is the other way the more radical $B$ median delegates too radical in response to $\alpha^{P^{*}}=\bar{\alpha}$ and there is too much haggling.

\subsection{Aggregate Waste with Simultaneous Delegation with asym- metric Medians}

Without loss of generality we again assume $\alpha^{M}<\beta^{M}$. Thus we know $\beta^{P^{*}}=\bar{\beta}$, and $\alpha^{P^{*}}=$ $\frac{\bar{\beta} \alpha^{M}}{\left(2 \bar{\beta}-\alpha^{M}\right)}$ and we can derive $W_{n d}=R \frac{\alpha^{M}}{2}$. $W_{n d}$ we know from above.

For the difference in aggregate waste, $\Delta W=W_{n D}-W_{D}$, it holds unambiguously that

$$
\operatorname{sgn}[\Delta W]=\operatorname{sgn}\left[R \frac{\beta^{M} \alpha^{M}}{\beta^{M}+\alpha^{M}}-R \frac{\alpha^{M}}{2}\right]=\operatorname{sgn}\left[\beta^{M}-\alpha^{M}\right]=+1
$$

This leads to the following proposition. 
Proposition 9 Simultaneous delegation leads to social improvement due to a reduction in aggregate waste in the case of asymmetric countries.

Again this result is due to the (by delegation extremely pronounced) asymmetry of the equilibrium.

\subsection{Aggregate Waste with Simultaneous Delegation with symme- tric Medians}

Here we compare all equilibria with respect to the aggregate waste. To do so we again express $m_{A}$ and $m_{B}$ as functions of $\alpha^{P}$ and $\beta^{P}$ and use the fact that $\alpha^{M}=\beta^{M}=\gamma$. Thus we get for the aggregate waste $m_{A}+m_{B}=R \frac{\gamma}{2}$ which is constant over all equilibria. Intuitively, as there is no initial difference to be amplified delegation apparently looses its bite in the symmetric case.

\section{Extensions}

\subsection{Heterogeneity with Respect to the Cost of Public Good Pro- vision}

Again looking at the median citizens' problems we can allow for differing efficiency $c_{A}$ and $c_{B}$ in providing the public good. A higher value for $c_{A}$ or $c_{B}$ expresses here a higher opportunity cost of resources spent in the contest as more of the public good consumption is foregone.

$$
\begin{aligned}
& u_{A}^{M}=\alpha^{M} R \frac{m_{A}}{m_{A}+m_{B}}+c_{A}\left(b_{A}-m_{A}\right) \\
& u_{B}^{M}=\beta^{M} R \frac{m_{B}}{m_{A}+m_{B}}+c_{B}\left(b_{B}-m_{B}\right)
\end{aligned}
$$

The analysis is basically the same as above and leads to equilibrium expenses in the contest 
given by

$$
m_{A}=R \frac{\left(\frac{\alpha^{P}}{c_{A}}\right)^{2}\left(\frac{\beta^{P}}{c_{B}}\right)}{\left(\left(\frac{\alpha^{P}}{c_{A}}\right)+\left(\frac{\beta^{P}}{c_{B}}\right)\right)^{2}} \text { and } m_{B}=R \frac{\left(\frac{\alpha^{P}}{c_{A}}\right)\left(\frac{\beta^{P}}{c_{B}}\right)^{2}}{\left(\left(\frac{\alpha^{P}}{c_{A}}\right)+\left(\frac{\beta^{P}}{c_{B}}\right)\right)^{2}} .
$$

Using that we can solve for the best responses in the politician type space, again similar to above:

$$
\alpha^{P^{*}}=\frac{c_{A} \beta^{P} \alpha^{M}}{2 \beta^{P} c_{A}-\alpha^{M} c_{B}} \text { and } \beta^{P^{*}}=\frac{c_{B} \alpha^{P} \beta^{M}}{2 \alpha^{P} c_{B}-\beta^{M} c_{A}}
$$

Now performing comparative statics with respect to the efficiency of public goods provision, $c_{A}$ and $c_{B}$, leads us to conclude that an increase in the efficiency of public good provision, e.g. better developed infrastructure, leads to less radical delegation, i.e. an inward shift of the best response function, and thus has the same effect as a lower valuation of the median citizen:

$$
\frac{\partial \alpha^{P^{*}}}{\partial c_{A}}=-\alpha^{M} \beta^{P} \frac{c_{B} \alpha^{M}}{\left(c_{B} \alpha^{M}-2 c_{A} \beta^{P}\right)^{2}}<0 \text { and } \frac{\partial \beta^{P^{*}}}{\partial c_{B}}=-\beta^{M} \alpha^{P} \frac{c_{A} \beta^{M}}{\left(c_{A} \beta^{M}-2 c_{B} \alpha^{P}\right)^{2}}<0
$$

Proposition 10 Better developed countries tend to delegate less radical.

\subsection{Group Composition}

One question to ask is whether there are incentives to affect the composition of groups. To do so we analyze the median voter's utility and see how it is affected along two margins: The identity of the median voter and the most extreme type.

Without loss of generality we focus again on the case where $\beta^{M}>\alpha^{M}$ holds. Thus the equilibrium politician types are given by $\beta^{P^{*}}=\bar{\beta}$ and $\alpha^{P^{*}}=\frac{\bar{\beta} \alpha^{M}}{\left(2 \bar{\beta}-\alpha^{M}\right)}$. Using $\alpha^{P^{*}}, \beta^{P^{*}}, m_{A}^{*}$, and $m_{B}^{*}$ we can write the equilibrium utilities of country $A$ and $B$ median voters as 


$$
u_{A}^{M}=\frac{1}{4} R \frac{\left(\alpha^{M}\right)^{2}}{\bar{\beta}}+b_{A}
$$

and

$$
u_{B}^{M}=\frac{1 R}{4} \frac{\left(\alpha^{M}-2 \bar{\beta}\right)\left(\alpha^{M}-2 \beta^{M}\right)}{\bar{\beta}}+b_{B}
$$

respectively.

Taking a look at the comparative statics with respect to $\alpha^{M}$ and $\bar{\beta}$ we get for $u_{B}^{M}$ that $\frac{\partial u_{B}^{M}}{\partial \alpha^{M}}=-\frac{1}{2} \frac{R}{\bar{\beta}}\left(\bar{\beta}+\beta^{M}-\alpha^{M}\right)<0$ and $\frac{\partial u_{B}^{M}}{\partial \bar{\beta}}=-\frac{1}{4} R_{\overline{\bar{\beta}}^{2}}\left(\alpha^{M}-2 \beta^{M}\right)>0$ as we assumed $\beta^{M}>\alpha^{M}$. For $u_{A}^{M}$ the results are clearcut $\frac{\partial u_{A}^{M}}{\partial \alpha^{M}}>0$ and $\frac{\partial u_{A}^{M}}{\partial \bar{\beta}}<0 .{ }^{6}$

The following proposition summarizes these findings.

Proposition 11 The initially more radical country $B$ median voter would like to reduce the other country's median voter type even further and would like to be able to delegate to an even more radical group member itself. The initially less radical country A median voter's incentive regarding group composition are the exact opposite.

The exact interpretation of these derivatives will differ depending on the specific application at hand. In some circumstances we can interpret this as countries competing for the group members with the strongest preferences for the rent. Suppose $\bar{\alpha}>\bar{\beta}$, then country $B$ has two advantages from attracting $\bar{\alpha}$. On the one hand $\bar{\beta}$ increases and on the other hand $\alpha^{M}$ decreases. These two effects soften the conflict by amplifying the asymmetry and thus increase $B^{\prime} s$ utility.

\footnotetext{
${ }^{6}$ Where the first derivative, $\frac{\partial u_{A}^{M}}{\partial \alpha^{M}}$, has to be carefully interpreted, as increasing $\alpha^{M}$ almost by definition has to increase the median voter's utility as it directly increases the valuation of the rent and not only has an indirect strategic effect.
} 


\subsection{Financing of the Budget}

We assumed so far that the spending in the contest is financed with an equal per capita tax. Now suppose that the financing of the contest spending is done by a tax that increases in the citizen's valuation for the contested rent. In this situation delegating to a more radical politician loses its commitment power, as the more radical politician is less inclined to fight. The reason is, that fighting hard for him is now relatively more expensive then for a less radical politician. As we have seen above the loss of delegation as an instrument may be even from a social planner's perspective be bad as aggregate waste increases. This might be one of the reasons why many policies are financed from a general budget and not on the basis of valuation dependent fees.

\subsection{Budget Restrictions}

We have argued above that spending in the contest strictly increases in the politician's type. If we invert the argument we can state that delegation helps the median to commit to a certain level of spending. From this point of view a budget restriction has the same effect as the existence of a most radical type in a country.

We can distinguish between two cases. If the budget restriction of the less radical country is binding there is neither a qualitative nor a quantitative effect as this is as if the most radical type of this country is reduced. But in equilibrium this has no effect. Only if the budget is really low there may be a quantitative effect as the country has to back down even more then it initially intended. If the budget restriction of the more radical country is binding it is again as if the most radical type in this country is reduced. This has an immediate quantitative effect as the median can de facto not delegate as radical as he wants. There is also a qualitative effect as soon as the 'effective' most radical type is sufficiently small. Then the initially less radical but richer country can exploit the fact that the more radical 
but poor country cannot exercise its higher desire to win the contest. In this context Rajan and Zingales' (2000) finding that ex-ante (efficient) trades might not happen in the face of potential conflicts down the road has relevance also in our context. If a trade is mutually beneficial but might increase budgets sufficiently to spur conflict later on the fear from the fiercer contest to come might hinder trades from taking place.

\section{Conclusion}

This paper presented a model of delegation in contests. We have shown that the equilibria that tend to arise seem to be characterized by a high degree of asymmetry. This can be due to two factors. In the sequential game, the asymmetry was simply due to the first mover advantage in the delegation game. Using this advantage, the first moving group could secure itself a higher share of the expected rent. Even, in the simultaneous game asymmetry is almost certain to arise although for different reasons. Here we found that a median group member that is only slightly more radical than her opponent in the other group will decide to give the active role in the contest to its most radical and aggressive member. The other group's median accommodates by delegating to a rather moderate politician. Thus initial asymmetries are amplified by delegation. Further we showed that delegation in contests implies by its asymmetry that less resources will be spent in the contest than under nondelegation.

If one is willing to go some way in interpreting our model one could interpret the US electing the hawkish Ronald Reagan in 1981 being followed by dovish Mikhail Gorbachev coming into power in the USSR in 1985 as being consistent with the predictions of our sequential model. Next to this, admittedly anecdotal, evidence we would like to stress that the main implications of our model are in principle testable. Our model identifies not only the circumstances under which the median group member will be decisive, but although to whom he wants to delegate the decision and what resource spending in the contest this 
implies. Finally, our model predicts extremely asymmetric spending of both groups in the contest.

It appears to be that the reasoning applied in this paper can be fruitfully enriched and applied to other issues. As well in the field of public choice as in other fields such as Industrial Organization. Baye and Hoppe (2003) explored the conditions under which contests and R\&D competitions are strategically equivalent. Consider a situation where two firms compete in two different markets. By hiring a CEO who is, e.g. due to private benefits, clearly in favor of one of the markets (thus more inclined to spend money on R\&D in this market) the two firms can avoid intense competition on both markets and both secure themselves their market with barely challenged monopoly rents. An example of a somewhat related reasoning for intra-firm conflicts can be found in Rotemberg and Saloner (1995).

\section{Appendix}

\subsection{Derivation of Reaction Function for General Constant Re- turns to Scale Contest Success Function}

Utility of country $A$ citizen is

$u_{A}=\alpha^{i} R \frac{\theta m_{A}}{\theta m_{A}+\pi m_{B}}+\left(b_{A}-m_{A}\right)$

and utility of country $B$ citizen is

$u_{B}=\beta^{i} R \frac{\pi m_{B}}{\theta m_{A}+\pi m_{B}}+\left(b_{B}-m_{B}\right)$.

From the FOCs we can derive the reaction functions in the contest stage

$$
m_{A}=\frac{\sqrt{R \alpha^{i} \pi m_{B}}}{\sqrt{\theta}}-\frac{m_{B} \pi}{\theta} \text { and } m_{B}=\frac{\sqrt{m_{A} R \beta^{i} \theta}}{\sqrt{\pi}}-\frac{m_{A} \theta}{\pi}
$$


and derive the equilibrium spending

$$
m_{A}^{*}=R \frac{\beta^{i}\left(\alpha^{i}\right)^{2} \theta \pi}{\left(\beta^{i} \pi+\alpha^{i} \theta\right)^{2}} \text { and } m_{B}^{*}=R \frac{\left(\beta^{i}\right)^{2} \alpha^{i} \theta \pi}{\left(\beta^{i} \pi+\alpha^{i} \theta\right)^{2}}
$$

The problem of the median citizens in countries $A$ and $B$ is given by

$$
\begin{array}{ll}
\max _{\alpha^{P}} & u_{A}=\alpha^{M} R \frac{\theta m_{A}}{\theta m_{A}+\pi m_{B}}+\left(b_{A}-m_{A}\right) \\
\max _{\beta^{P}} & u_{B}=\beta^{M} R \frac{\pi m_{B}}{\theta m_{A}+\pi m_{B}}+\left(b_{B}-m_{B}\right)
\end{array}
$$

or using the equilibrium values for $m_{A}^{*}$ and $m_{B}^{*}$ as

$$
\begin{array}{ll}
\max _{\alpha^{P}} & R \frac{\alpha^{M}\left(\alpha^{P}\right)^{2} \theta^{2}+\alpha^{M} \alpha^{P} \beta^{P} \theta \pi-\beta^{P}\left(\alpha^{P}\right)^{2} \theta \pi}{\left(\beta^{P} \pi+\alpha^{P} \theta\right)^{2}} \\
\max _{\beta^{P}} & R \frac{\beta^{M} \pi \beta^{P} \alpha^{P} \theta+\beta^{M}\left(\beta^{P}\right)^{2} \pi^{2}-\left(\beta^{P}\right)^{2} \alpha^{P} \theta \pi}{\left(\beta^{P} \pi+\alpha^{P} \theta\right)^{2}} .
\end{array}
$$

Again we can derive the reaction functions in the politicians type space

$$
\begin{aligned}
\alpha^{P} & =\frac{\pi \alpha^{M} \beta^{P}}{2 \pi \beta^{P}-\theta \alpha^{M}} \\
\beta^{P} & =\frac{\theta \beta^{M} \alpha^{P}}{\left(2 \theta \alpha^{P}-\pi \beta^{M}\right)}
\end{aligned}
$$

which are qualitatively equivalent to our formulation. Thus our results hold for this more general formulation, too.

\subsection{Derivation of the Reaction Function}

Here we proof the optimality of delegating to $\bar{\alpha}$ if $\beta^{P}<\frac{\alpha^{i} \bar{\alpha}}{\left(2 \bar{\alpha}-\alpha^{i}\right)}$. 
For $\beta^{P} \in\left[\frac{\alpha^{i}}{2}, \frac{\alpha^{i} \bar{\alpha}}{\left(2 \bar{\alpha}-\alpha^{i}\right)}\right]$ the optimality is shown by checking that left of the reaction function, i.e. for $\alpha^{P}<\frac{\alpha^{i} \alpha^{P}}{2 \alpha^{P}-\alpha^{i}}$ utility is strictly increasing in $\alpha^{P}$.

The derivative $\frac{\partial u}{\partial \alpha^{P}}$ is given by

$$
\frac{\partial u}{\partial \alpha^{P}}=\frac{R \beta^{P}}{\left(\alpha^{P}+\beta^{P}\right)^{3}}\left(\alpha^{i} \alpha^{P}+\alpha^{i} \beta^{P}-2 \alpha^{P} \beta^{P}\right) .
$$

Thus we know that

$$
\operatorname{sgn}\left(\frac{\partial u}{\partial \alpha^{P}}\right)=\operatorname{sgn}\left(\alpha^{i} \alpha^{P}+\alpha^{i} \beta^{P}-2 \alpha^{P} \beta^{P}\right) .
$$

Left of the reaction function it holds that $\alpha^{P}=k \frac{\alpha^{i} \alpha^{P}}{2 \alpha^{P}-\alpha^{i}}$ for $k<1$.

Plugging this in gives $\operatorname{sgn}\left(\frac{\partial u}{\partial \alpha^{P}}\right)=+1$ for $k<1$.

For $\beta \in\left(0, \frac{\alpha^{i}}{2}\right]$ we repeat the exercise:

$$
\frac{\partial u}{\partial \alpha^{P}}=\frac{R \beta^{P}}{\left(\alpha^{P}+\beta^{P}\right)^{3}}\left(\alpha^{i} \alpha^{P}+\alpha^{i} \beta^{P}-2 \alpha^{P} \beta^{P}\right) .
$$

Thus again we know that

$$
\operatorname{sgn}\left(\frac{\partial u}{\partial \alpha^{P}}\right)=\operatorname{sgn}\left(\alpha^{i} \alpha^{P}+\alpha^{i} \beta^{P}-2 \alpha^{P} \beta^{P}\right) .
$$

Now we check for $\beta^{P}<\frac{\alpha^{i}}{2}$, i.e. $\beta^{P}=k \frac{\alpha^{i}}{2}$ for $k<1$ that utility is strictly increasing in $\alpha^{P}$.

$$
\operatorname{sgn}\left(\frac{\partial u}{\partial \alpha^{P}}\right)=\operatorname{sgn}\left(\alpha^{i} \alpha^{P}(1-k)+\alpha^{i} \frac{k \alpha^{i}}{2}\right)=+1
$$

As utility is strictly increasing in $\alpha^{P}$ it is optimal to choose in these cases $\alpha^{P}=\bar{\alpha}$.

\subsection{Utility Comparison in the Sequential Move Game}

Without loss of generality we assume that the country $A$ politician moves first. From the analysis we know that $\alpha^{P^{*}}=\bar{\alpha}$ and $\beta^{P^{*}}=\frac{\bar{\alpha} \beta^{M}}{2 \bar{\alpha}-\beta^{M}}$. 
The utility of the first mover is (after using our results on $m_{A}$ and $m_{B}$ ) given by

$$
u_{A}=\frac{R \alpha^{M}\left(\alpha^{P}\right)^{2}+R \alpha^{M} \alpha^{P} \beta^{P}-R\left(\alpha^{P}\right)^{2} \beta^{P}}{\left(\alpha^{P}+\beta^{P}\right)^{2}}+b_{A} .
$$

The utility of the second mover is (after using our results on $m_{A}$ and $m_{B}$ ) given by

$$
u_{B}=\frac{R \beta^{M}\left(\beta^{P}\right)^{2}+R \beta^{M} \alpha^{P} \beta^{P}-R \alpha^{P}\left(\beta^{P}\right)^{2}}{\left(\alpha^{P}+\beta^{P}\right)^{2}}+b_{B} .
$$

Now use $\alpha^{P^{*}}=\bar{\alpha}$ and $\beta^{P^{*}}=\frac{\bar{\alpha} \beta^{M}}{2 \bar{\alpha}-\beta^{M}}$ and assume $b_{A}=b_{B}=b$.

$$
\begin{aligned}
& u_{A}=b+\frac{\bar{\alpha}^{3} R}{\left(\bar{\alpha}+\frac{\bar{\alpha} \beta^{M}}{2 \bar{\alpha}-\beta^{M}}\right)^{2}} \\
& u_{B}=b+\frac{\bar{\alpha}^{3} R}{\left(\bar{\alpha}+\frac{\bar{\alpha} \beta^{M}}{2 \bar{\alpha}-\beta^{M}}\right)^{2}} \frac{\left(\beta^{M}\right)^{2}}{\left(2 \bar{\alpha}-\beta^{M}\right)^{2}}
\end{aligned}
$$

Now it is easily seen that $u_{A}>u_{B}$ whenever

$$
\frac{\left(\beta^{M}\right)^{2}}{\left(2 \bar{\alpha}-\beta^{M}\right)^{2}}<1
$$

For $\bar{\alpha}$ sufficiently large, i.e. $\bar{\alpha}>2 \beta^{M}$, this is always true.

\section{References}

1. Baik, K.H., and Kim, I.-G (1997) 'Delegation in Contests,' European Journal of Political Economy, Vol. 13(2), pp. 281-298

2. Baik, K.H., Kim, I.-G., and Na, S. (2001) 'Bidding for a Group-Specific Public-Good Prize,' Journal of Public Economics, Vol. 82(3), pp. 415-429

3. Baik, K. H. and J. F. Shogren (1992) 'Strategic Behavior in Contests: Comment,' American Economic Review, Vol. 82(1), pp. 359-362 
4. Barro, R. J. and D.B. Gordon (1983a) 'Rules, Discretion and Reputation in a Model of Monetary Policy,' Journal of Monetary Economics, Vol. 12, pp. 101-120

5. Barro, R. J. and D.B. Gordon (1983b) 'A Positive Theory of Monetary Policy in a Natural Rate Model,' Journal of Political Economy, Vol. 91(4), pp. 589-610

6. Baye, M.R and Hoppe, H.C. (2003) 'The Strategic Equivalence of Rent-Seeking, Innovation, and Patent-Race Games,' Games and Economic Behavior, Vol. 44(2), pp. $217-26$

7. Baye, M. R., D. Kovenock and C. DeVries (1993) 'Rigging the lobbying process: An application of the all-pay-auction,' American Economic Review, Vol. 83(1), pp. 289-294

8. Besley, T. and S. Coate (1997) 'An Economic Model of Representative Democracy,' The Quarterly Journal of Economics, Vol. 112(1), pp. 85-114

9. Black, D. (1948) 'On the Rationale of Group Decision-making,' The Journal of Political Economy, Vol. 56, pp. 23-34

10. Dijkstra, B.R. (1998) 'Cooperation by way of support in a rent seeking contest for a public good,' European Journal of Political Economy, Vol. 14(4), pp. 703-725

11. Dixit, A. (1987) 'Strategic behavior in contests', American Economic Review, Vol. 77(5), pp. 891-898.

12. Garfinkel, M. R. (1990) 'Arming as a Strategic Investment in a Cooperative Equilibrium,' American Economic Review, Vol. 80(1), pp. 50-68

13. Hilman, A., and J. Riley (1989) 'Politically Contestable Rents and Transfers', Economics and Politics, Vol. 1, pp. 17-39

14. Konrad, K.A. (2004) 'Bidding in Hierarchies,' European Economic Review, Vol. 48(6), pp. $1301-1308$ 
15. Konrad, K.A., Peters, W., and Warneryd, K. (2004)'Delegation in First-Price All-Pay Auctions,' Managerial and Decision Economics, Vol. 25(5), pp. 283-290

16. Lazear, E. P. and S. Rosen (1981) 'Rank-Order Tournaments as Optimum Labor Contracts,' Journal of Political Economy, Vol. 89(5), pp. 841-864

17. Moscovici, S. and M. Zavalloni (1969) 'The group as a polarizer of attitudes,' Journal of Personality and Social Psychology, Vol. 12, pp. 123-135

18. Nitzan, S. (1994) 'Modelling Rent-Seeking Contests,' European Journal of Political Economy, Vol. 10(1), pp. 41-60

19. Oren, I. (1992) 'A Theory of Armament,' Ph.D. Dissertation, University of Chicago

20. Oren, I. (1994) 'The Indo-Pakistani Arms Competition: A Deductive and Statistical Analysis,' Journal of Conflict Resolution, Vol. 38(2), pp. 185-214.

21. Osborne, M. J. and A. Slivinski (1996) 'A Model of Political Competition with CitizenCandidates,' The Quarterly Journal of Economics, Vol. 111(1), pp. 65-96

22. Persson, T. and G. Tabellini (2000) 'Political Economics - Explaining Economic Policy,' MIT Press

23. Rajan, R.G. and L. Zingales (2000) 'The tyranny of inequality,' Journal of Public Economics, Vol. 76, pp. 521-558

24. Rotemberg, J. J. and G. Saloner (1995) 'Overt Interfunctional Conflict (and its Reduction Through Business Strategy),' RAND Journal of Economics, Vol. 26(4), pp. 630-653

25. Schoonbeek, L. (2004) 'Delegation in a group-contest,' European Journal of Political Economy, Vol. 20(1), pp. 263-272

26. Teger, A.I. and D.G. Pruitt (1967) 'Components of group risk taking,' Journal of Experimental Social Psychology, Vol. 3, pp. 189-205 
27. Tullock, G. (1980) 'Efficient Rent Seeking,' in Buchanan et al (Editor), Toward a Theory of the Rent-Seeking Society, Texas A \& M University Press 


\title{
CESifo Working Paper Series
}

\author{
(for full list see www.cesifo-group.de)
}

1589 Kazuo Ogawa, Elmer Sterken and Ichiro Tokutsu, Bank Control and the Number of Bank Relations of Japanese Firms, November 2005

1590 Bruno Parigi and Loriana Pelizzon, Diversification and Ownership Concentration, November 2005

1591 Claude Crampes, Carole Haritchabalet and Bruno Jullien, Advertising, Competition and Entry in Media Industries, November 2005

1592 Johannes Becker and Clemens Fuest, Optimal Tax Policy when Firms are Internationally Mobile, November 2005

1593 Jim Malley, Apostolis Philippopoulos and Ulrich Woitek, Electoral Uncertainty, Fiscal Policy and Macroeconomic Fluctuations, November 2005

1594 Assar Lindbeck, Sustainable Social Spending, November 2005

1595 Hartmut Egger and Udo Kreickemeier, International Fragmentation: Boon or Bane for Domestic Employment?, November 2005

1596 Martin Werding, Survivor Benefits and the Gender Tax Gap in Public Pension Schemes: Observations from Germany, November 2005

1597 Petra Geraats, Transparency of Monetary Policy: Theory and Practice, November 2005

1598 Christian Dustman and Francesca Fabbri, Gender and Ethnicity - Married Immigrants in Britain, November 2005

1599 M. Hashem Pesaran and Martin Weale, Survey Expectations, November 2005

1600 Ansgar Belke, Frank Baumgaertner, Friedrich Schneider and Ralph Setzer, The Different Extent of Privatisation Proceeds in EU Countries: A Preliminary Explanation Using a Public Choice Approach, November 2005

1601 Jan K. Brueckner, Fiscal Federalism and Economic Growth, November 2005

1602 Steven Brakman, Harry Garretsen and Charles van Marrewijk, Cross-Border Mergers and Acquisitions: On Revealed Comparative Advantage and Merger Waves, November 2005

1603 Erkki Koskela and Rune Stenbacka, Product Market Competition, Profit Sharing and Equilibrium Unemployment, November 2005

1604 Lutz Hendricks, How Important is Discount Rate Heterogeneity for Wealth Inequality?, November 2005 
1605 Kathleen M. Day and Stanley L. Winer, Policy-induced Internal Migration: An Empirical Investigation of the Canadian Case, November 2005

1606 Paul De Grauwe and Cláudia Costa Storti, Is Monetary Policy in the Eurozone less Effective than in the US?, November 2005

1607 Per Engström and Bertil Holmlund, Worker Absenteeism in Search Equilibrium, November 2005

1608 Daniele Checchi and Cecilia García-Peñalosa, Labour Market Institutions and the Personal Distribution of Income in the OECD, November 2005

1609 Kai A. Konrad and Wolfgang Leininger, The Generalized Stackelberg Equilibrium of the All-Pay Auction with Complete Information, November 2005

1610 Monika Buetler and Federica Teppa, Should you Take a Lump-Sum or Annuitize? Results from Swiss Pension Funds, November 2005

1611 Alexander W. Cappelen, Astri D. Hole, Erik Ø. Sørensen and Bertil Tungodden, The Pluralism of Fairness Ideals: An Experimental Approach, December 2005

1612 Jack Mintz and Alfons J. Weichenrieder, Taxation and the Financial Structure of German Outbound FDI, December 2005

1613 Rosanne Altshuler and Harry Grubert, The Three Parties in the Race to the Bottom: Host Governments, Home Governments and Multinational Companies, December 2005

1614 Chi-Yung (Eric) Ng and John Whalley, Visas and Work Permits: Possible Global Negotiating Initiatives, December 2005

1615 Jon H. Fiva, New Evidence on Fiscal Decentralization and the Size of Government, December 2005

1616 Andzelika Lorentowicz, Dalia Marin and Alexander Raubold, Is Human Capital Losing from Outsourcing? Evidence for Austria and Poland, December 2005

1617 Aleksander Berentsen, Gabriele Camera and Christopher Waller, Money, Credit and Banking, December 2005

1618 Egil Matsen, Tommy Sveen and Ragnar Torvik, Savers, Spenders and Fiscal Policy in a Small Open Economy, December 2005

1619 Laszlo Goerke and Markus Pannenberg, Severance Pay and the Shadow of the Law: Evidence for West Germany, December 2005

1620 Michael Hoel, Concerns for Equity and the Optimal Co-Payments for Publicly Provided Health Care, December 2005

1621 Edward Castronova, On the Research Value of Large Games: Natural Experiments in Norrath and Camelot, December 2005 
1622 Annette Alstadsæter, Ann-Sofie Kolm and Birthe Larsen, Tax Effects, Search Unemployment, and the Choice of Educational Type, December 2005

1623 Vesa Kanniainen, Seppo Kari and Jouko Ylä-Liedenpohja, Nordic Dual Income Taxation of Entrepreneurs, December 2005

1624 Lars-Erik Borge and Linn Renée Naper, Efficiency Potential and Efficiency Variation in Norwegian Lower Secondary Schools, December 2005

1625 Sam Bucovetsky and Andreas Haufler, Tax Competition when Firms Choose their Organizational Form: Should Tax Loopholes for Multinationals be Closed?, December 2005

1626 Silke Uebelmesser, To go or not to go: Emigration from Germany, December 2005

1627 Geir Haakon Bjertnæs, Income Taxation, Tuition Subsidies, and Choice of Occupation: Implications for Production Efficiency, December 2005

1628 Justina A. V. Fischer, Do Institutions of Direct Democracy Tame the Leviathan? Swiss Evidence on the Structure of Expenditure for Public Education, December 2005

1629 Torberg Falch and Bjarne Strøm, Wage Bargaining and Political Strength in the Public Sector, December 2005

1630 Hartmut Egger, Peter Egger, Josef Falkinger and Volker Grossmann, International Capital Market Integration, Educational Choice and Economic Growth, December 2005

1631 Alexander Haupt, The Evolution of Public Spending on Higher Education in a Democracy, December 2005

1632 Alessandro Cigno, The Political Economy of Intergenerational Cooperation, December 2005

1633 Michiel Evers, Ruud A. de Mooij and Daniel J. van Vuuren, What Explains the Variation in Estimates of Labour Supply Elasticities?, December 2005

1634 Matthias Wrede, Health Values, Preference Inconsistency, and Insurance Demand, December 2005

1635 Hans Jarle Kind, Marko Koethenbuerger and Guttorm Schjelderup, Do Consumers Buy Less of a Taxed Good?, December 2005

1636 Michael McBride and Stergios Skaperdas, Explaining Conflict in Low-Income Countries: Incomplete Contracting in the Shadow of the Future, December 2005

1637 Alfons J. Weichenrieder and Oliver Busch, Artificial Time Inconsistency as a Remedy for the Race to the Bottom, December 2005

1638 Aleksander Berentsen and Christopher Waller, Optimal Stabilization Policy with Flexible Prices, December 2005 
1639 Panu Poutvaara and Mikael Priks, Violent Groups and Police Tactics: Should Tear Gas Make Crime Preventers Cry?, December 2005

1640 Yin-Wong Cheung and Kon S. Lai, A Reappraisal of the Border Effect on Relative Price Volatility, January 2006

1641 Stefan Bach, Giacomo Corneo and Viktor Steiner, Top Incomes and Top Taxes in Germany, January 2006

1642 Johann K. Brunner and Susanne Pech, Optimum Taxation of Life Annuities, January 2006

1643 Naércio Aquino Menezes Filho, Marc-Andreas Muendler and Garey Ramey, The Structure of Worker Compensation in Brazil, with a Comparison to France and the United States, January 2006

1644 Konstantinos Angelopoulos, Apostolis Philippopoulos and Vanghelis Vassilatos, RentSeeking Competition from State Coffers: A Calibrated DSGE Model of the Euro Area, January 2006

1645 Burkhard Heer and Bernd Suessmuth, The Savings-Inflation Puzzle, January 2006

1646 J. Stephen Ferris, Soo-Bin Park and Stanley L. Winer, Political Competition and Convergence to Fundamentals: With Application to the Political Business Cycle and the Size of Government, January 2006

1647 Yu-Fu Chen, Michael Funke and Kadri Männasoo, Extracting Leading Indicators of Bank Fragility from Market Prices - Estonia Focus, January 2006

1648 Panu Poutvaara, On Human Capital Formation with Exit Options: Comment and New Results, January 2006

1649 Anders Forslund, Nils Gottfries and Andreas Westermark, Real and Nominal Wage Adjustment in Open Economies, January 2006

1650 M. Hashem Pesaran, Davide Pettenuzzo and Allan G. Timmermann, Learning, Structural Instability and Present Value Calculations, January 2006

1651 Markku Lanne and Helmut Luetkepohl, Structural Vector Autoregressions with Nonnormal Residuals, January 2006

1652 Helge Berger, Jakob de Haan and Jan-Egbert Sturm, Does Money Matter in the ECB Strategy? New Evidence Based on ECB Communication, January 2006

1653 Axel Dreher and Friedrich Schneider, Corruption and the Shadow Economy: An Empirical Analysis, January 2006

1654 Stefan Brandauer and Florian Englmaier, A Model of Strategic Delegation in Contests between Groups, January 2006 